\title{
Generation I(mmersion) - How to Meet Learner Expectations of Tomorrow
}

\author{
http://dx.doi.org/10.3991/ijac.v9i1.5241 \\ Kai Erenli \\ University of Applied Sciences bfi Vienna, Vienna, Austria
}

\begin{abstract}
Today's teachers mainly belong to the so-called "Generation $X "$ while learners are most often described as "Generation Y" or "Millennials". Most current discussions of learning methods are being held in view of the status quo. But what about the learners of tomorrow? What expectations do the learners of tomorrow have? Which methods and tools will the teachers of tomorrow have in stock to meet these expectations? "The old learning spaces, dominated by the immensely successful organizations of the industrial era like schools and universities, are struggling to maintain authority and control over the definition and certification of knowledge while at the same time remaining true to the stated mandate of helping to equip people and society for a life where learning is much more heterogeneous and heterarchical'[11]. Therefore, wouldn't it be good to have a toolset ready and be able to choose the appropriate tools and techniques right on time? Reflecting on publications, expert interviews and state-of-the-art best practices, this paper attempts to draw a picture of the future (e-)learning scenario. To give the next generation a name, "Generation I(mmersion)" was chosen by the author. Despite breaking the $X, Y, Z$ sequence, this name highlights the state of "Immersion", which educators and learners of tomorrow will/might find themselves in.
\end{abstract}

Index Terms-Teaching Methods, Generation I, Immersive Learning, Future Learning

\section{INTRODUCTION}

"I hear and I forget. I see and I remember. I do and I understand." This quote by Kong Qiu, better known as Confucius, from some 2,500 years ago describes a scenario that educators and students have been recreating ever since. Due to recent technological developments - in today's world immersive learning scenarios allow learners to experience learning content in-depth - we seem to be closer to the realization of this scenario than ever before:

In other words: the Uncanny Valley [1] seems to have been crossed! The Uncanny Valley refers to a hypothesis made by robotics professor Mori in 1970 in which he stated that "as the appearance of a robot is made more human, some observers' emotional response to the robot will become increasingly positive and empathic, until a point is reached beyond which the response quickly becomes that of strong revulsion. However, as the robot's appearance continues to become less distinguishable from that of a human being, the emotional response becomes positive once again and approaches human-to-human empathy levels. The "valley" refers to the dip in a graph of the comfort level people have with the robots and examples can not only be found in the field of robotics but also in $3 \mathrm{D}$ animation. Those fields serve as the (technical) fertile soil for the creation of immersive experiences that enable learners to "do" as suggested by Confucius.

This paper takes a look at the history of education, the changes and developments that could be witnessed over the past decades To be in a position to make a prediction, online databases were employed using "teaching generation [n]" as search terms. Searching for "teaching generation $x$ " resulted in 2,870,000 hits, "teaching generation y" yielded 2,690,000 hits, "teaching future generations" led to 584,000 hits. These $6,144,000$ results were reviewed using filters, such as "education", "education reform", "teaching method", "education trends" or "future learning". Finally, out of the $6,144,000$ hits, a database containing 2,642 references was accumulated and joint positions were identified. Additionally, statistical data was analyzed and compared to any result.

Trends over time are reflected in this paper (therefore citations here represent common findings at a given time) and have helped to answer the following questions:

1. Which teaching methods can be observed since the beginning of formal learning?

2. Which trends can be observed looking at the past 40 years of higher education?

3. Is it possible to predict a future trend of education?

\section{A. Education from "information preservation only" to the birth of modern teaching methods}

Naturally humankind had to learn in order to survive and evolve. Formal learning goes back to sometime between 3,500 and 500 B.C.E and was established in ancient Egypt [2]. Libraries have been in existence since 2,600 B.C.E. [3]. While the majority of the (about 6,000-item) tablet corpus retrieved from the Royal Library of Ashurbanipal included colloquial compositions in the form of foreign correspondences, legislation and engagements, aristocratic declarations, and financial matters, other texts contained omens, divinations, incantations and hymns to various gods and furthermore even notations of medicine, astronomy and literature [4]. It can be assumed, therefore, that knowledge worth storing on a stone tablet not only covered basic elements of modern society but also preserved philosophical or religious thoughts. Yet education methods were not established on a broad level. Education was reserved for an elite minority.

It was not until the 1600 s that formal education became available to a broad audience [5]. During the next 200 years much legislation introduced tax laws that approved money for public education, e.g. the Scottish Education Act 1633, or made major improvements to public school systems. For instance, Horace "Mann's Reform" beginning in 1837 was a huge effort towards modern education 
in the US taking the Prussian education system as a role model. Nevertheless, such reforms only established the fertile soil for teaching methods yet to be developed and initiated discussions about "the art of teaching": pedagogy. Even though the term pedagogy itself derives from the Greek word $\pi \alpha 1 \delta \alpha \gamma \omega \gamma i \alpha$ (paidagōgia), literally meaning "to lead the child", the willingness to deal with this subject is a rather new discipline.

\section{B. Education as we know it}

In 1949 Donald Hebb's "The Organization of Behavior" [6] introduced a new rule, often referred to as Hebb's Law, which linked brain science to learning: "Neurons that fire together wire together" [7]. Even though this rule (which explains why students experience anxiety regarding certain subjects, such as physics once they have associated a negative emotion with this subject) was well recognized among neuroscientists of the time, it did not have a major impact on education as such. Rising interest in this matter filled scientific papers and books in the decades to come and resulted in a general popularization of information on neuroscientific research, bringing together neuroscience, education and psychology.

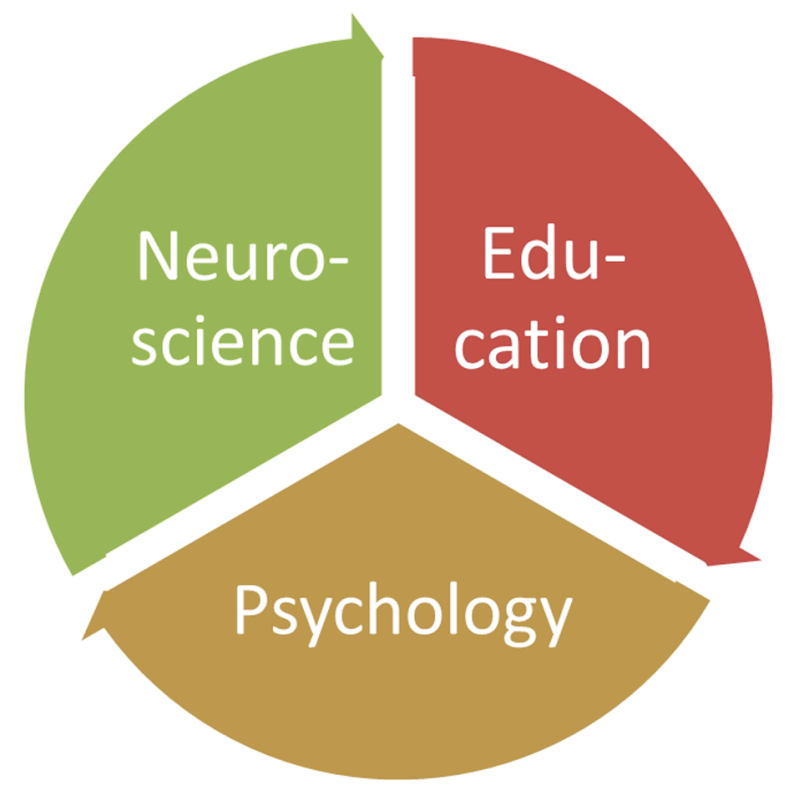

Figure 1. The "Classic" Education Circle

These topics imposed new standards and demands on the fast-growing education market, yet the accelerated tempo of consumption, rationalized by the enlightened idea of progress, did not facilitate going beyond the attempt to match current psychological theories with educational-technological developments as stated by Blanco and Rosa [8]. Today's educators most often struggle hard enough to keep up with state-of-the-art learning methods [9] as well as the possibilities made available by alwaysimproving technologies.

Significant changes that could be witnessed over the past few decades have made learning trajectories more diverse and complex. As stated in the European Commission's Report on the Future of Learning [10], these changes can be observed as:

- changing age profiles of the population;

- shifting structures of employment;
- a more intimate mixing of the local and the global; households with diverse and more complex roles;

- social networks becoming more visible and more valued;

- professional identities and associated skills becoming more blurred in most occupations;

- people finding their values and learning in likeminded communities;

- work and learning moving into new public and private spaces; and

- experiences that become communities of practices and projects (immersive learning).

It seems that the job of educator has never been as demanding as today. Unfortunately, this path may lead to a big gap within education as many educators may not be able to keep up with this speed, resulting in frustration, demotivation and skepticism towards innovative tools and new methods. If educators lose faith in their toolbox, a dystopian future will become reality for the generation to come.

But there is hope. Looking at the road education has taken since the idea of individualized learning styles was established in the 1970s (see e.g. [11] and [12]) and ever criticized thereafter (see e.g. [13]), based on a scientific best guess a future trend seems rather easy to identify nonetheless, since these ideas originate from learning simultaneously being individual and collective, active and reflective and also defined by its context [14]. Therefore, starting with what was state-of-the-art some 35 years ago makes a lot of sense as it marks the timeframe of people who still participate as educators or learners today.

Even though the labels Generation X, Y or Z are often criticized as being too broad, bearing the risk of oversimplification or not being precise enough, they will continue to be used to refer to the educators and students of the past 30 to 40 years.

\section{THE 1980s: EDUCATION FOR GENERATION X - "WHAT IS IT ALL GOOD FOR?"}

Born between 1961 and 1981, Generation Xers embarked on higher education predominantly in the 1980s. People belonging to this generation can be described as being much more comfortable with technology, diversity and global awareness than any previous generation. Due to technological progress they were the first generation to grow up with CDs, remote controls and most notably computers. They were also one of the first generations to benefit from easier world travel and access to world-wide current events.

Interestingly, the 1980 s became a time of great uncertainty regarding the path education should take. For instance, since conventional wisdom held that "schools don't make a difference" [15], one of the biggest concerns in the US was the quality of American education. Many studies and surveys of the time evaluated the ambitious aims of the reform programs of the 1960s [16]. Most of them concluded that if you compared education with family background, schools had relatively little influence on students' chances in life, thus justifying the deconstruction of the curriculum and the lowering of standards [17].

The US commission's report A Nation at Risk [18] became the paradigmatic educational statement of the $80 \mathrm{~s}$, 
resulting in a reform of teacher education and the teaching profession.

Two of the reform reports on teacher education came into the spotlight. On the one hand, "Tomorrow's Teachers" by the Holmes Group [19], a consortium of deans and a number of chief academic officers from research institutions across the US, among other aspects suggested the "transformation of teaching from an occupation into a genuine profession" and called for an overhaul of teacher education. On the other hand, The Carnegie Task Force on Teaching as a Profession, a creation of the Carnegie Forum on Education and the Economy, endorsed restructuring schools to strengthen the role of teachers [20]. Interestingly enough, both emphatically recommended the abolishment of undergraduate degrees in education [21].

In a related move, the National Board for Professional Teaching Standards was created to develop examinations on which to base national certification of expert teachers. In the end, each and every subject area in the curriculum became the object of close scrutiny and demands for reform. The reports on mathematics education "Everybody Counts" and science education "Science for All Americans" represented state-of-the-art thinking in these fields [15]. Ravitch has stated that "whatever else the 80's were, they were a decade when politicians and educators and business leaders concluded that we must not choose between quality and equality."

Even though the evaluation studies of that time raised many red flags, the 2011 "Generation X Report" [22] based on annual surveys used in the longitudinal study of today's adults described Generation $\mathrm{X}$ to be highly educated, active, balanced, happy and family-oriented.

Instead, the new roles of the educator in postmodern society as stated by Sacks [23] should be recognized as:

1. guiding students in the use of information-gathering tools; and

2. helping students imagine new ways of looking at knowledge.

In short: Generation X education was affected by extensive controversy over pedagogy as a whole, whether it regarded teaching methods or technical skills. The battle of the right mix of elements (Fig. 1) had just begun. And the (technological) tools available at the time were not even taken into consideration yet. So, how did this affect the education of the next generation?

\section{THE 1990S: EDUCATION FOR GENERATION Y - ANYWHERE, ANYTIME}

The next generation - Generation Y or the Millennials - is the demographic cohort following Generation X. According to common sources, there are no precise dates when this generation starts and ends. Researchers and commentators use birth years ranging from the early 1980 s to the early 2000 s. Therefore, Generation Y encountered the accomplishments subsequent to the controversies during the 1980s. The "no future" Generation X gave way to the "has no clue where we are going" Generation Y [10].

In a large-sample $(\mathrm{n}=7,705)$ study of college students, Junco and Mastrodicasa [24] collected research-based information on the personality profiles of this generation, especially as it relates to higher education. They found that college students belonging to Generation $\mathrm{Y}$ were frequently in touch with their parents and used technology at higher rates than people from prior generations. In their survey, $99 \%$ of students used the Internet for research or homework, 97\% owned a computer, 94\% owned a cell phone, and $56 \%$ owned an MP3 player. Other findings in the survey revealed that $76 \%$ of students used instant messaging, 92\% thereof reported multitasking while instant messaging, $40 \%$ got most of their news from television whereas $34 \%$ used the Internet as their primary news source.

Therefore, the outcome was clear: Technology had entered the field [see also 25]. The notions of "learning anywhere and anytime" as well as "availability of education $24 / 7 / 365$ " began to spread while resentment towards using these then new technologies faded.
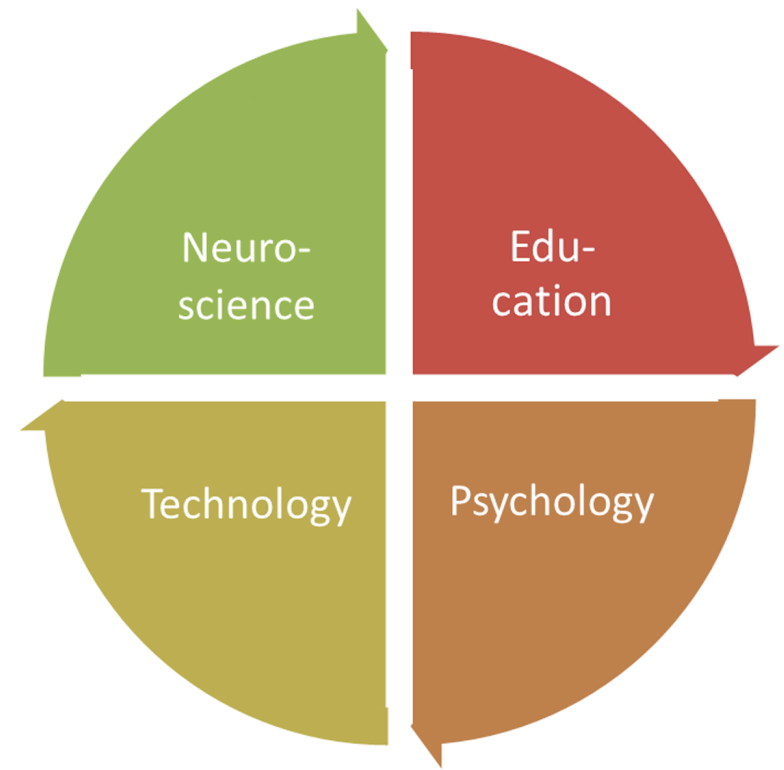

Figure 2. The Education Circle of Generation Y

In 2005 people belonging to Generation Y were described as "independent, entrepreneurial thinkers who relish responsibility, demand immediate feedback, and expect a sense of accomplishment hourly. They thrive on challenging work and creative expression, love freedom and flexibility, and hate micromanagement" [26].

Upon reflecting the development education has taken over the past $40+$ years, it makes sense to take a look at state-of-the-art teaching methods and learning styles. Most of them result from the previous findings related to the education circles shown in Figs. 1 and 2. Since the advent of the Internet and the new media many new approaches have been taken in the field of education, hypes were born and have vanished again. Ultimately, expectations of education and educators have been raised as awareness of best practices has resulted in a "so-my-teacher-should-deliver(at-least-)the-same" attitude.

Fortunately enough, in 2004 a research team explored thousands of learning style models in a joint analytical project [27]. Unfortunately, in their work they criticized most of the main instruments used to identify an individual's learning style. Coffield's team stated that none of the then most popular learning style theories had been adequately validated through independent research. Thus, 
they arrived at the conclusion that the idea of a "learning cycle", the consistency of visual, auditory and kinesthetic preferences (known as the VAK model) following the approach by Dunn and Dunn [28], and the value of matching teaching and learning styles were all "highly questionable".

Interestingly enough, the VAK model was and is widely used in schools in the United States. Nevertheless, Coffield's team drew the following conclusion: "Despite a large and evolving research programme, forceful claims made for impact are questionable because of limitations in many of the supporting studies and the lack of independent research on the model." Although the authors heavily criticized many well-known research publications on learning styles, they recommended some of them as "appraised as promising". The Cognitive Style Index by Allinson and Hayes [29], for instance, was considered to have the best psychometric credentials.

In conclusion, the team recommended the use of their findings so that these models would help to develop selfawareness and metacognition since pedagogy on its own was considered insufficient. They stated that it would be beneficial for educators in the field to have instruments scrutinized and analyzed by experts to obtain accurate tools for their field.

Five years later the open-access journal "Psychological Science in the Public Interest" also published a report [30] on the scientific validity of learning style practices. The authors concluded that appropriate evaluation of the learning styles hypothesis - the notion that optimal learning demands that students receive instruction tailored to their respective learning styles — would require a particular kind of study and suggested a different evaluation. One of their findings was that studies utilizing this essential research design were virtually absent from the learning styles literature. Furthermore, the panel was able to find only a few studies that had used this research design, and all but one of them had come to negative results.

The one study indicating a positive finding concluded that the same learning method was superior for all kinds of students. The authors noted, however, that even if the requisite finding were obtained, the benefits would need to be large and not just statistically significant before learning style interventions could be recommended as costeffective. That is, the cost of evaluating and classifying students by their learning style and then providing customized instruction would need to be more beneficial than other interventions. As a consequence, the panel found, "at present, there is no adequate evidence base to justify incorporating learning styles assessments into general educational practice. Thus, limited education resources would better be devoted to adopting other educational practices that have a strong evidence base, of which there are an increasing number" [30].

To conclude, the hot topic in the education of Generation Y (and all other learners as well) was the exploration of the "learning style myth". After all, the efficacy of congruent teaching-learning styles in the classroom was called into question. Unfortunately, there is no clear answer or scientific proof for either side. Instead, it is common ground to assume that learning behavior differs and that learners get their motivation differently.

In this context publications by Csíkszentmihályi [33 and 34] get cited regularly. He mentions "flow" (also referred to as "zone") - a mental state of operation in which a person is fully immersed in a feeling of energized focus, full involvement, and enjoyment of the process while performing an activity. In essence, flow is characterized by complete absorption in what one is doing combined with staying motivated while the activity lasts. Even though this concept must sound promising to educators and learners alike, there is no scientific proof of it, yet. What does this tell us for upcoming trends?

\section{EDUCATION FOR GENERATION I(MMERSION) - IS THIS REAL?}

Even though the "I" was already in use as abbreviation for the Internet, the next generation should be referred to as "Immersion" for reasons to be explained below.

Since the rise of immersive environments like "Second Life ${ }^{\text {TM", }}$ the topic has emerged among educators across the globe. Even though Second Life ${ }^{\mathrm{TM}}$ did not become a communication or education standard, it opened up the field of immersive technologies and techniques for educational purposes far beyond the simple usage of virtual worlds. Virtual reality head-mounted displays, such as Oculus Rift ${ }^{\mathrm{TM}}$ or the Microsoft ${ }^{\mathrm{TM}}$ HoloLens $^{\mathrm{TM}}$, are considered the next big thing. Even Second Life ${ }^{\mathrm{TM}}$ stands a chance to get back into the spotlight [31] by connecting the platform to Oculus Rift ${ }^{\mathrm{TM}}$. Regarding teaching, immersive education has become a well-covered field (46,400 hits in online databases). Therefore, it seems useful to take a closer look at immersion and its related stages as foundation in the wide field of education.

Immersion itself is described in Wikipedia as " a metaphoric use of the experience of submersion applied to representation, fiction or simulation". Immersion can also be defined as the state of consciousness where "a physical self is transformed by being surrounded in an artificial environment; used for describing partial or complete suspension of disbelief, enabling action or reaction to stimulations encountered in a virtual or artistic environment. The degree to which the virtual or artistic environment faithfully reproduces reality determines the degree of suspension of disbelief. The greater the suspension of disbelief, the greater the degree of presence achieved."

With regard to education three stages of immersion can be observed:

\section{- engagement,}

- engrossment, and

- total immersion [35],

which can be combined with the different kinds of immersion described by a game designer [36]:

- tactical immersion is experienced while performing tactile operations that involve skill. Persons feel the flow described earlier in this paper while performing actions that result in success.

- strategic immersion is associated with mental challenges experienced while persons are trying to optimize a situation (e.g. chess players attempting to calculate the right move).

- narrative immersion occurs when players become invested in a story and is similar to what is experienced while reading a book or watching a movie. 
Narrative immersion has been a big topic in research on artificial intelligence since the early stages of computer science. It was not possible to visualize stories in a way that was considered appropriate but it was possible to use text-based stories. The behavior of the player was analyzed and player immersion into the story could be observed. Moreover it was assessed if by using the players' answers a computer could gain knowledge of its own [37]. Nowadays, the visualization barrier can be crossed (e.g. by state-of-the-art video games and movies). The education of Generation I(mmersion) thus looks as follows:

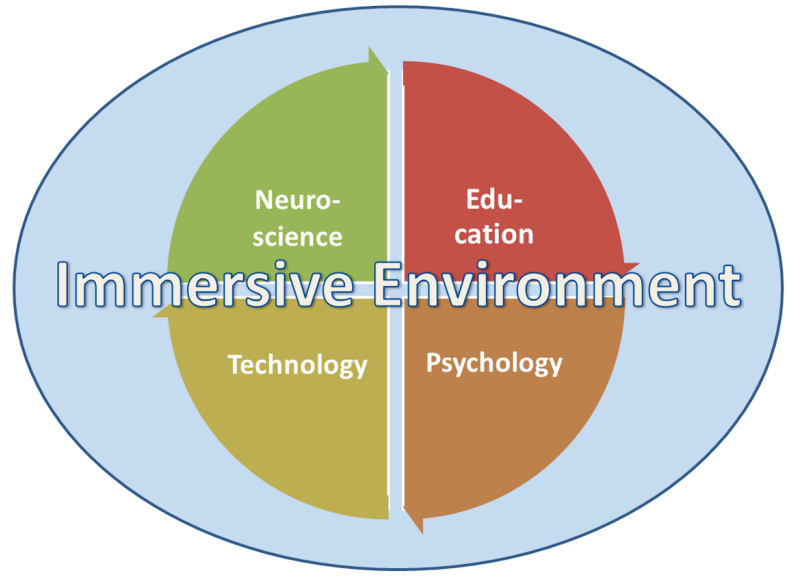

Figure 3. The Education Circle of Generation I(mmersion)

All aspects shown before in Figs. 1 and 2 can be mixed together using an Immersive Environment. If an educator wants to teach law in ancient Rome, for instance, he or she can "travel in time" and perform a moot court in a realistic visualization of the environment, thus immersing him- or herself in ancient times. This may be done using a VRheadset" (Technology) - can also be done in an nondigital way - after having prepared the content (Education) and having designed the reception of the visualization (Neuroscience and Psychology). The Immersive Environment serves as a melt-down and facilitator for the different aspects of the circle.

Therefore, observing the road education has taken and looking at the technological developments of the past 10 years as well as today's trends, it seems that immersive environments and methods cannot be overlooked or considered hype anymore. A short look at the indicators will provide proof.

\section{EDUCATION TRENDS FOR GENERATION I(MMERSION) - INDICATORS, HOPES \& FEARS}

The following indicators were found filtering the publications by date. Publications representing indicators were published from 2011. The indicators were presented to a variety of educators and learners $(n=58)$. Additionally these were asked about their hopes and fears regarding the development of immersive education looking at the indicators they just got presented.

\section{A. Indicators}

The indicators identified are based on actual trends in the entertainment industries and best practices in education. These indicators have been sorted randomly but represent a plurality of hits in the filtered publications list.
- $4 D$ cinemas can most often be found in today's theme parks and combine a 3D film with physical effects (e.g. rain, wind, strobe lights, or vibration) that occur in the theatre in synchronization with the film. The physical effects aim to immerse viewers in the 3D effects.

- immersive experiences in TV series road shows: utilizing Oculus Rift VR headsets, a game engine, wind machines, real elevators and rumble packs users can enter the world of the TV series Game of Thrones to experience an immersive virtual reality. The installation was developed "to change the course of how a narrative experience can be delivered" [38].

- game-based learning: data analysis has found that classes experiencing game-based learning had significantly higher means than those that did not [39]. Looking at this trend, the rise of gamified elements in education ("gamification"), the development and evaluation of serious games for various usages (e.g. Exergames), video games like "Minecraft" or authoring tools like "Scratch" for teaching purposes is well under way.

- design thinking is becoming a big topic by aiding school administrators to solve institution-based problems, educators to develop more creative lesson plans and students to engender design thinking. Currently many researchers are exploring the intersection of design thinking and education.

- state-of-the-art teaching methods, such as flipped classrooms, combining personalized blended learning and video lectures, MOOCs or selfassessed-learning demonstrate that methods that were once individually considered best practice are now being merged together and seem easier to selfassess, monitor and moderate globally.

Therefore, it can be seen that all trends not only mix all aspects shown in Fig. 3 but also try to immerse learners in the best possible way. Further scientific evaluation of the indicators identified is strongly advised.

\section{B. Hopes \& Fears}

Stakeholders have informed us about their hopes regarding these indicators:

- increase in interaction, collaboration

- bigger toolset, method mix in teaching

- being able to convey practical knowledge more efficiently than before

- making "learning-on-demand" available

- achieving "flow" in learners (yet to be proved to exist)

and also their fears:

- staying behind in a global market

- slow transition

- stagnation and frustration due to excessive demand for available skills

- difficult to monitor sustainability of learning using new methods and tools

- failing to identify the best mix of methods and tools due to a vast number of methods available

- failing to implement tasks 
Furthermore, transformations at the level of learner motivation and the behavioral dimension also seem to become a major topic.

\section{CONCLUSION}

It stands to reason that in order to create an immersive environment for learners educators nowadays have to provide a big range of skills regarding but not limited to:

- technology,

- psychology,

- cognitive science,

- teaching didactics,

- storytelling,

- intercultural skills, and

- knowledge management.

The ongoing discussion of the right way to teach and learn has wound up in a controversy about the right balance when mixing recognized best practices. Even though the different models of learning styles have not proven to be valid, the evolution of immersive tools and methods may dispense with this debate as a whole. Understandably, an immersive environment addresses all learning styles whether they are visual, aural, verbal, kinesthetic, social or solitary. Thus the need to personalize teaching gets waived. The question if Generation I will benefit from these developments can only be answered by future research.

Therefore, the quote by Confucius at the beginning of this paper can be followed up with a quote by a storyteller of today, Mr. Spielberg: "We're never going to be totally immersive as long as we're looking at a square, whether it's a movie screen or whether it's a computer screen. We've got to get rid of that and we've got to put the player inside the experience, where no matter where you look you're surrounded by a three-dimensional experience. That's the future"[41].

\section{REFERENCES}

[1] M. Mori, The uncanny valley (K. F. MacDorman \& N. Kageki, Trans.). IEEE Robotics \& Automation Magazine 1970, 19(2), pp. 98-100. http://dx.doi.org/10.1109/MRA.2012.2192811

[2] J. Assmann, The mind of Egypt: history and meaning in the time of the Pharaohs, Harvard Press: 2003, p.48.

[3] L. Casson, Libraries in the Ancient World. Yale University Press, 2002. p. 3.

[4] S. Parpola, Assyrian Library Records. Journal of Near Eastern Studies, 1983, vol 42(1), pp.1-29. http://dx.doi.org/10.1086/372 983

[5] T. Tokuhama-Espinosa, Mind, Brain, and Education Science: A Comprehensive Guide to the New Brain-Based Teaching, Norton 2011, p. 42

[6] D. Hebb, The Organization of Behaviour, A Neuropsychological Theory, 1949. John Wiley \& Sons.

[7] The mnemonic phrase is usually attributed to C. Shatz at Stanford University, referenced for example in N. Doidge, The Brain That Changes Itself, 2007: Viking Press. p. 427.

[8] F. Blanco, A. Rosa, Dilthey's Dream, Teaching History to Understand the Future, International Journal of Educational Research, Volume 27, Number 3, 1997, pp. 189-200(12)189

[9] P. E. Monk, E. J. Irons, N. Leffel Carlson, E. Kirk, L. M. Stephens, K. Abernathy, Higher Education: Generational Percep- tions of Faculty/Student Classroom Behaviors, Attitudes, and Technology Integration, http://www.nssa.us/tech journal/volum e 1-1/vol1-1 article6.htm Retrieved 15 May 2015.

[10] R. Miller, H. Shapiro, K. E. Hilding-Hamann, School's Over: Learning Spaces in Europe in 2020: An Imagining Exercise on the Future of Learning, 2008, http://ipts.jrc.ec.europa.eu/publications/ pub.cfm?id=1780, Retrieved 15 May 2015.

[11] R. L. Daniels/ J.P. Stevens, The interaction between the internalexternal locus of control and two methods of college instruction, American Educational Research Journal 13, 1976, pp. 103-113. http://dx.doi.org/10.2307/1162763

[12] J. Parent, J. Forward, R. Cantor, J. Mohling, Interactive effects of teaching style and personal locus of control on student performance and satisfaction. Journal of Educational Psychology, 67, 1975 pp. 764-769. http://dx.doi.org/10.1037/0022-0663.67.6.764

[13] H. Pashler; M. McDaniel, D. Rohrer, R. Bjork, Learning styles: Concepts and evidence, Psychological Science in the Public Interest 9 (2008), pp. 105-119.

[14] J.P. Gavigan, F. Scapolo, A comparison of national foresight exercises, Foresight 1.6 (1999), pp. 495-517. http://dx.doi.org/10.1108/14636689910802368

[15] D. Ravitch, Education in the 1980's: A Concern for 'Quality', http://www.edweek.org/ew/articles/1990/01/10/09200009.h09.htm 1?tkn=LOZFMfBp5Askk515JxdRXeUVoxMeMXFBXh6a, Retrieved 15 May 2015.

[16] B.L. Rogers, Teaching and Social Reform in the 1960s: Lessons from National Teacher Corps Oral Histories, Oral History Review Volume 35, Number 1, Winter/Spring 2008, http://muse.jhu.edu/ journals/oral history review/v035/35.1.rogers.pdf, Retrieved 15 May 2015. http://dx.doi.org/10.1093/ohr/ohn022

[17] D. Gardner et al., A Nation At Risk: The Imperative For Educational Reform. An Open Letter to the American People. A Report to the Nation and the Secretary of Education, 1983, Superintendent of Documents, Government Printing Office, Washington, DC 20402 (Stock No. 065-000-00177-2)

[18] J. Coleman, The concept of equality of educational opportunity Harvard Educational Review 1968, 38(1), pp. 7-22. http://dx.doi.org/10.17763/haer.38.1.m3770776577415m2

[19] The Holmes Group, Tomorrow's Teachers, http://files.eric.ed.gov/ fulltext/ED270454.pdf, Retrieved 15 May 2015.

[20] Carnegie Task Force on Teaching as a Profession, A nation prepared: Teachers for the 21st Century. Carnegie Corporation, New York (1986).

[21] S.P. Wiggins, Revolution in the Teaching Profession: A Comparative Review of Two Reform Reports, http://www.ascd.org/ASCD/ pdf/journals/ed_lead/el_198610_wiggins.pdf, Retrieved 15 May 2015.

[22] J. Miller, Jon, The Generation X Report: Active, Balanced, and Happy: These Young Americans are not Bowling Alone, Longitudinal Study of American Youth 2011 - University Of Michigan. http://lsay.org/GenX Rept Iss1.pdf, Retrieved 15 May 2015.

[23] P. Sacks, Generation X Goes to College. An Eye-Opening Account of Teaching in Postmodern America, Open Court Publishing Company, 332 South Michigan Avenue, Suite 2000, Chicago, IL 60604, 1996.

[24] R. Junco, J. Mastrodicasa,, Connecting to the Net.Generation: What Higher Education Professionals Need to Know About Today's Students. National Association of Student Personnel Administrators 2007.

[25] R. Berk, A. Ronald, How Do You Leverage the Latest Technologies, including Web 2.0 Tools, in Your Classroom? International Journal of Technology in Teaching and Learning 62009 (1): 4. Retrieved 2 September 2010.

[26] C. Martin, From high maintenance to high productivity: What managers need to know about Generation $Y$, Industrial and Commercial Training, 2005, Industrial and Commercial Training 2005 37:1, pp. 39-44. http://dx.doi.org/10.1108/00197850510699965

[27] F. Coffield, D. Moseley, E. Hall, K. Ecclestone, Learning styles and pedagogy in post-16 learning: A systematic and critical review. (2004).

[28] R.S. Dunn, K.J. Dunn, G.E. Price, Learning style inventory (LSI) 1989, Price Systems, Incorporated (PO Box 1818, Lawrence 66044). 
PAPER

GENERATION I(MMERSION) - HOW TO MEET LEARNER EXPECTATIONS OF TOMORROW

[29] C.W. Allinson, J. Hayes, The cognitive style index: A measure of intuition-analysis for organizational research, Journal of Management studies, 33(1), 1996, pp. 119-135. http://dx.doi.org/10.1111/j.1467-6486.1996.tb00801.x

[30] H. Pashler, M. McDaniel, D. Rohrer, R. Bjork, Learning styles: Concepts and evidence. Psychological Science in the Public Interest 9: (2008), pp. 105-119.

[31] https://community.secondlife.com/t5/Featured-News/Oculus-RiftDK2-Project-Viewer-Now-Available/ba-p/2843450, Retrieved 15 May 2015.

[32] J.C. Spoon, J.W. Schell, Aligning student learning styles with instructor teaching styles Journal of Industrial Teacher Education, 35, 1998, pp. 41-56.

[33] M. Csikszentmihalyi, "Flow and the Psychology of Discovery and Invention." HarperPerennial, New York (1997).

[34] M. Csikszentmihalyi "Flow" Springer Netherlands, 2014. http://dx.doi.org/10.1007/978-94-017-9088-8_15

[35] J. Reid, E. Geelhoed, R. Hull, K. Cater, B. Clayton, Parallel worlds: immersion in location-based experiences, in CHI'05 extended abstracts on Human factors in computing systems 2005 pp. 1733-1736

[36] http://designersnotebook.com/Columns/063 Postmodernism/063 postmodernism.htm, Retrieved 15 May 2015.
[37] P.D. Lebling, M.S. Blank, T.A. Anderson, Zork: A Computerized Fantasy Simulation Game", IEEE Computer 12 (4), April 1979: pp. 51-59. http://dx.doi.org/10.1109/MC.1979.1658697

[38] http://www.framestore.com/work/game-thrones-ascend-wall-vrexperience, Retrieved 15 May 2015.

[39] R. Blunt, Does game-based learning work? Results from three recent studies, in Proceedings of the Interservice/Industry Training, Simulation, \& Education Conference 2007, pp. 945-955. [40]

[41] G. Lucas, S. Spielberg: Studios Will Implode; VOD Is the Future, http://variety.com/2013/digital/news/lucas-spielberg-on-future-ofentertainment-1200496241/, Retrieved 15 May 2015.

\section{AUTHOR}

Erenli, Kai works at the University of Applied Sciences BFI Vienna as Director of the Department of Film, TV and Media Production, A-1030 Vienna, Austria (e-mail: kai.erenli@fh-vie.ac.at).

This article is an extended and modified version of a paper presented at the the International Conference on E-learning in the Workplace 2015 (ICELW'15), held in June 2015, at Columbia University in New York, NY, USA. Submitted 6 July 2015. Published as resubmitted by the author 8 September 2015. 